\title{
Coordination in a Single-Retailer Two-Supplier Supply Chain under Random Demand and Random Supply with Disruption
}

\author{
Fei Hu, ${ }^{1}$ Cheng-Chew Lim, ${ }^{2}$ Zudi Lu, ${ }^{3}$ and Xiaochen Sun ${ }^{1}$ \\ ${ }^{1}$ Department of Mathematics, School of Science, Tianjin University, Tianjin 300072, China \\ ${ }^{2}$ School of Electrical and Electronic Engineering, The University of Adelaide, Adelaide, SA 5005, Australia \\ ${ }^{3}$ School of Mathematical Sciences, The University of Adelaide, Adelaide, SA 5005, Australia \\ Correspondence should be addressed to Xiaochen Sun; xcsun@tju.edu.cn
}

Received 17 October 2012; Accepted 29 December 2012

Academic Editor: Xiang Li

Copyright (C) 2013 Fei Hu et al. This is an open access article distributed under the Creative Commons Attribution License, which permits unrestricted use, distribution, and reproduction in any medium, provided the original work is properly cited.

\begin{abstract}
This paper studies the coordination issue of a supply chain consisting of one retailer and two suppliers, a main supplier and a backup supplier. The main supplier's yield is subject to disruption and the retailer faces a random demand. We determine the retailer's optimal ordering policy and the main supplier's production quantity that maximize expected profit of the centralized supply chain. We also analyze the decentralized scenario, and a combination of overproduction risk sharing and buy-back contracts with a side payment from/to the backup supplier is provided to coordinate the supply chain. Numerical examples are given to gain some qualitative insights.
\end{abstract}

\section{Introduction}

This paper studies the coordination issue of a supply chain among one retailer and two suppliers under random demand and supply disruption. Different from the previous research that focuses on the supplier's random yield, we consider the supply disruption, during which the output of the production is zero. We also propose an overproduction risk sharing (OPRS) and buy-back contracts with a side payment for supply chain coordination. Since our work touches upon two areas of research: random yield with disruption and contracts in a supply chain with demand uncertainty, we confine ourselves to reviewing the following related works of these two topics.

In general, any production or logistics process is somewhat related to random yield; that is, with equal amount input, the output of the production usually varies. Due to damage that occurs during transferring, any transportation process can also be viewed as random yield process [1]; for example, in the liquid crystal display manufacturing industry, it is quite common to get a production yield of less than $50 \%$. Then the actual response of the supplier to the retailer's order will be mandated by the supply contract between them; for example, if the cost of tracking partial orders is high or the transportation costs are high, the supply contract may specify delivery in a single shipment with the uncertainty in delivery time [2]; in other situations, the manufacturer may agree to accept partial shipment of the order quantity [3].

Gerchak and Grosfeld-Nir [4] analyzed the tradeoff between setup cost and production cost when making batch production decisions, where both the random yield and random demand follow a general discrete distribution. Granot and Yin [5] investigated the effect of sequential commitment in the decentralized newsvendor model with price-dependent demand, where the supplier and the retailer sequentially commit on prices and quantities. Mukhopadhyay and $\mathrm{Ma}$ [6] developed a single-period model to evaluate the optimal procurement and production decisions with uncertain demand and random yield of the used parts under three different cases. Wang [7] investigated the traditional and vendor-managed inventory arrangements in a supply chain and obtained the optimal production/inventory decisions under random yield and uncertain demand for both arrangements. He and Zhang [8] studied a seller/supplier commitment contract with minimum delivery commitment and analyzed the supply chain with the risk sharing contract 
under a constant secondary market price- and a yielddependent secondary market price. He and Zhao [9] investigated the ordering policy of the retailer, raw material planning decision of the supplier, and the optimal contracts for a three-level supply chain with random yield and demand. Gurnani et al. [10] considered an assembly problem, where a firm faces random demand for a final product and a general yield distribution of two critical components from the individual suppliers. Using the modified cost function, they determined the combined component ordering quantity and assembly decisions for the firm. In the model of Güler and Bilgiç [11], they studied the coordination of an assembly system for arbitrary number of suppliers with random demand and random yield and established the concavity of expected supply chain profit and proposed two mixed type of contracts to coordinate the chain under forced compliance. Under the wholesale price contract, Keren [12] analyzed a two-tier supply chain, where a distributor facing a deterministic demand procures a product from a producer confronting a random production yield. And an analytical solution to the distributor's ordering decision is derived when the production yield follows the uniform distribution. Li et al. [13] extended and provided new results on the supply chain model with producer's random yield proposed by Keren [12]. They derived analytic solutions of the supply chain decisions under generalized yield distribution and pointed out that the distributor should order more than the demand if and only if his/her marginal profit from selling this product exceeds a threshold.

Supply disruption is not considered by the above-cited literature on random yield. However, in a practical reality, a supplier may be unable to satisfy the production order for a variety of reasons, such as equipment failures, damaged facilities, problems in procuring the necessary raw materials, and so forth. With more and more enterprises starting to realize that supply disruption severely affects their ability to successfully manage their own supply chains, supply disruption management has received increasing attention. Many researchers have devoted much effort to studying this issue. Based on the sample firms, Hendricks and Singhal [14] estimated the short-term effects of supply disruption such as production or shipment delays on shareholder value. They found that glitch announcements decrease shareholder value by $10.82 \%$. Furthermore, Hendricks and Singhal [14] investigated the long-term negative effects of supply disruption on the financial performance of firms based. They found that the average abnormal stock returns of firms that experienced disruptions is nearly $40 \%$ and the firms cannot quickly recover from the negative effects of a disruption. Taking into account the disruption frequency and the loss of market share, Pochard [15] analyzed the value and the benefits of dual sourcing. Oke and Gopalakrishnan [16] investigated the types and management of risks in a retail supply chain. Yu et al. [17] studied the sourcing decision alternatives between single sourcing and dual sourcing in a two-stage supply chain, where the demand is price-sensitive and the market scale increases when a supply disruption occurs. Sarkar and Mohapatra [18] considered the risks of supply disruption due to occurrence of super, semisuper, and unique events and determined the optimal size of supply base. Tomlin [19] studied a singleproduct model in which a firm can source from a cheap but unreliable supplier and/or an expensive but reliable supplier. They established supplier characteristics and firm characteristics in determining the firm's optimal strategy for managing supply disruption risk. Meena et al. [20] developed an analytical model to determine the optimal number of suppliers under different failure probability, capacity, and compensation. Li et al. [21] investigated the sourcing strategy of a retailer and the pricing strategies of two suppliers in a supply chain with supply disruption. For more existing supply disruption models, we refer to the review in Snyder and Shen [22].

Since double marginalization [23] will directly lead to inefficient performance of the supply chain, coordination of activities among the different members in the supply chain is necessary for the whole supply chain's effective management. A great deal of effort has been devoted to researching the supply chain coordination issues. All kinds of popular contracts have been explored in the literature for the supply chain coordination, such as buy-back contracts or returns policies [24-26], revenue sharing contracts [27, 28], wholesale price contracts $[27,29]$, risk sharing contracts [30], quantity discount policies [31], quantity flexibility contracts [32], sales rebate contracts [33], and so on. Recently, Ding and Chen [34] studied how to fully coordinate a three-level supply chain with a flexible return policies by setting the rules of pricing while postponing the determination of the final contract prices. He et al. [35] studied supply chain contracts and coordination when the downstream retailer faces both effort- and price-dependent stochastic demand. In such a situation, since all traditional contracts fail to coordinate the retailer's action and distort the retailer's marginal incentive to exert system optimal effort and price, none of them can coordinate the supply chain. Hence they explored a variety of other combined contracts and found that only a properly designed returns policy with a sales rebate and a penalty contract is able to achieve channel coordination and lead to a Pareto improving win-win situation for supply chain members. Xiao et al. [36] studied coordination of a twoechelon supply chain with consumer return and random demand, where consumers also face uncertainty in their valuations for products. Granot and Yin [5] investigated the effect of sequential commitment in the decentralized newsvendor model with price-dependent demand, where the supplier and the retailer sequentially commit on prices and quantities. van der Rhee et al. [37] propose a new spanning revenue sharing contract mechanism that the most downstream entity initiates a single contract involving all upstream entities for multiechelon supply chains, and analyzed the new revenue sharing contract in the linear supply chain setting with stochastic demand. Lin et al. [38] proposed an insurance contract under which the supplier shares the risk of overstock and understock with the retailer, and showed that the insurance contract can coordinate the supply chain with a newsvendor-type product. Li et al. [39] explored a generalized supply chain model and showed the double marginalization effect in the supply chain under supply uncertainty. When the demand is deterministic, a wholesale price contract and 
a shortage penalty contract is developed to coordinate the supply chain. When the demand is random, two equivalent coordination contracts (called accept-all type contracts for the buyer) are proposed to induce the supplier into the systematically optimal production input level.

The works by He and Zhang [40] and Hou et al. [41] are similar to our study here. He and Zhang [40] studied the effects of random yield in a decentralized supply chain and proposed several risk sharing contracts. They also compared the results of proposed contracts and found that random yield might enhance the supply chain performance and decrease the double marginalization effect under certain conditions. But there is no alternative sources available and the yield disruption is not considered in their paper. Hou et al. [41] investigated a buy-back contract between a buyer and a backup supplier when the buyer's main supplier is subject to disruption. They derived the buyer's optimal order quantity and the backup supplier's optimal return price under the recurrent supply uncertainty and the demand uncertainty, respectively. But in their study, the coordination mechanism between the main supplier is not concerned, and they do not investigate the buyer's optimal decision when both recurrent supply uncertainty and the demand uncertainty exist.

The majority of the literature considers that the yield is a stochastic proportion of the planned quantity and does not consider the coordination and the yield disruption in the chain, and most of the existing literature that studies the coordination mechanism is confined to the supply chain consisting of one retailer and one supplier. In this paper, we integrate the works of He and Zhang [40] and Hou et al. [41] and study the retailer's optimal ordering policy and the main supplier's optimal planned production quantity under random demand and random supply with disruption. We investigate the coordination between one retailer and two suppliers-one is a main source and the other is a backup, and show that two contracts with three components: overproduction risk sharing, buy-back, and a payment from/to the backup supplier cannot only coordinate our supply chain but also divide the whole chain's expected profit at any proportion among the three members.

The rest of the paper is organized as follows. In Section 2, we provide a description of the model. In Section 3, we study optimal solution for the integrated supply chain. In Section 4, both the retailer's decision and the main supplier's decision are given in the decentralized scenario. In Section 5, we argue that simple wholesale and overproduction risk sharing contract cannot coordinate the chain. A combination of overproduction risk sharing and buy-back contracts with a side payment from the backup supplier to the main supplier is provided to coordinate the chain. Numerical examples to illustrate further insights are provided in Section 5. Finally, some conclusions and further research topics are given in Section 6.

\section{Model Description}

We consider a single-period supply chain consisting of one retailer and two supplier with the assumption that the information is symmetrical, where one supplier (called main supplier) is unreliable with cheaper wholesale price, and the other supplier (called backup supplier) is perfectly reliable with more expensive wholesale price. This supply phenomenon is often seen in the off-shoring situation [42].

We use $L$ to denote the main supplier's decision on how many products to produce, and assume that the yields of the supplier will be $Y L$, where $Y$ is a random yield variable and positive support on $[0,1]$ which satisfies $P\{Y=0\}=p$ and $P\{0<Y \leqslant 1\}=\int_{0}^{1} g(y) d y=1-p=q$, where $g(y)$ is a nonnegative function (note that the yield is subject to disruption with a probability $p$, and $g(y)$ is not a probability density function unless $p=0$, i.e., there is no disruption). We assume that the backup supplier's production has a perfect yield, for example, the backup supplier can convert similar or better products from his inventory to satisfy the order. We also assume that the retailer faces a random demand, $X$, with cumulative distribution function, $F(x)$, probability density function, $f(x)$, and $E(X)=\mu_{X}$.

The main supplier's per unit production cost is $c_{m}$, and a marginal cost $\alpha c_{m}$ is incurred in the event of a disruption [21]. The unit understock cost to the retailer is $c_{u}$ (this cost may include loss of reputation). In order to mitigate supply risks, the retailer orders $Q$ units from the backup supplier at the beginning of the selling seasons. The main supplier's whole price is $w_{m}$ per delivery unit, and the backup supplier charges the retailer a wholesale price $w_{b}$ per delivery unit. The main supplier's production cost of each planned unit is $c_{m}$, and the unit production cost of the backup supplier is $c_{b}$. The retailer sells the products to the end customer at the unit price $s$. At the end of the selling season, all unsold products will be salvaged at a value of $v$ per unit.

Based on the reliability of the backup supplier, it is reasonable to assume that $c_{b}>c_{m}>v$. In addition, we assume that $s>w_{b}>c_{b}$ and $s>w_{m}>c_{m}$. These inequalities make sure that each member has a positive profit.

\section{Centralized Model}

To establish a performance benchmark, we first analyze the optimal solution of an integrated supply chain. In the centralized model, the expected integrated supply chain profit is given by

$$
\begin{aligned}
\Pi_{c}(Q, L)= & s E \min (X, Y L+Q)+v E(Y L+Q-X)^{+} \\
& -c_{u} E(X-Y L-Q)^{+}-c_{b} Q-\delta c_{m} L
\end{aligned}
$$

where $\delta=\alpha p+q$. The first term in (1) is the expected revenue from sales, the second term is the salvaged value, the third term is the opportunity costs due to the lost sales, and the last two terms are the production costs. 
From (1), the integrated supply chain's expected profit function can be rewritten as follows:

$\Pi_{c}(Q, L)$

$$
\begin{aligned}
& =p\left\{\int_{0}^{Q}[s x+v(Q-x)] f(x) d x\right. \\
& \left.\quad+\int_{Q}^{\infty}\left[s Q-c_{u}(x-Q)\right] f(x) d x\right\} \\
& +\int_{0}^{1}\left\{\int_{0}^{y L+Q}[s x+v(y L+Q-x)] f(x) d x\right. \\
& \left.\quad+\int_{y L+Q}^{\infty}\left[s(y L+Q)-c_{u}(x-y L-Q)\right] f(x) d x\right\} \\
& \quad \times g(y) d y-c_{b} Q-\delta c_{m} L .
\end{aligned}
$$

The following Proposition 1 states that the objective function in (2) is concave. Hence, the optimal production quantity and order quantity from the backup supplier can be determined easily. All proofs, if not provided in the paper, are in the appendix.

Proposition 1. $\Pi_{c}(Q, L)$ is jointly concave in $Q$ and $L$.

From Proposition 1, we can characterize the optimal order quantity, $Q^{c}$, and the optimal planned production quantity, $L^{c}$, through the first-order conditions. In particular, we have the following Proposition 2.

Proposition 2. (1) If $\delta c_{m}<c_{b} \mu_{Y}$ and $\int_{0}^{1} F\left(y L_{0}\right) g(y) d y<(s-$ $\left.c_{b}+c_{u}\right) /\left(s-v+c_{u}\right)$, then $\left(Q^{c}, L^{c}\right)$ is uniquely solved by

$$
\begin{gathered}
p F\left(Q^{c}\right)+\int_{0}^{1} F\left(y L^{c}+Q^{c}\right) g(y) d y=\frac{s-c_{b}+c_{u}}{s-v+c_{u}}, \\
\int_{0}^{1} y F\left(y L^{c}+Q^{c}\right) g(y) d y=\frac{\left(s+c_{u}\right) \mu_{Y}-\delta c_{m}}{s-v+c_{u}},
\end{gathered}
$$

where $L_{0}$ satisfies $\int_{0}^{1} y F\left(y L_{0}\right) g(y) d y=\left(\mu_{Y}\left(s+c_{u}\right)-\delta c m\right) /(s-$ $\left.v+c_{u}\right)$.

(2) If $\delta c_{m}<\mu_{Y} c_{b}$ and $\int_{0}^{1} F\left(y L_{0}\right) g(y) d y \geqslant\left(s-c_{b}+c_{u}\right) /(s-$ $\left.v+c_{u}\right)$, then $\left(Q^{c}, L^{c}\right)=\left(0, L_{0}\right)$. $\left.\left.\left.c_{u}\right)\right), 0\right)$.

(3) If $\delta c_{m} \geqslant \mu_{Y} c_{b}$, then $\left(Q^{c}, L^{c}\right)=\left(F^{-1}\left(1-\left(c_{b}-v\right) /(s-v+\right.\right.$

From Proposition 2, we can obtain the maximum expected profit of the integrated supply chain as follows:

$$
\Pi_{c}\left(Q^{c}, L^{c}\right)=\left(s-v+c_{u}\right) \pi\left(Q^{c}, L^{c}\right)-c_{u} \mu_{X},
$$

where $\pi\left(Q^{c}, L^{c}\right)=\int_{0}^{1} \int_{0}^{y L^{c}+Q^{c}} x f(x) g(y) d x d y+$ $p \int_{0}^{Q^{c}} x f(x) d x$.

\section{Decentralized Model under a Traditional Arrangement}

Now we consider the decentralized scenario under the traditional arrangement; that is, the two suppliers and the retailer are independent agents and derive their individual expected profit, respectively. At the beginning of the selling season, the retailer places an order quantity $R$ from the main supplier, and orders $Q$ units of products from the backup supplier in order to mitigate supply risks. It is worth mentioning that the retailer does not charge the main supplier any penalty for the unsatisfied orders caused by the supply risks, but when its delivery quantity is higher than $R$, the retailer accepts only the amount equal to $R$.

4.1. Main Supplier's Production decision. For given order quantity $R$, the expected profit of the main supplier is

$$
\Pi_{m}(L)=w_{m} E \min (Y L, R)+v E(Y L-R)^{+}-\delta c_{m} L .
$$

Here, the first term is the supplier's revenue from the retailer's order, the second term is the salvaged value, and the last term is the production costs.

Proposition 3. For given $R$, the main supplier's optimal planned production quantity $L^{*}(R)=\zeta R$, where $\zeta$ is independent of $R$ and is determined by the following:

$$
\left(w_{m}-v\right) \int_{0}^{1 / \zeta} y g(y) d y=\delta c_{m}-v \mu_{Y}
$$

Proof. Taking the first and second derivatives in (6), we obtain

$$
\begin{gathered}
\frac{d \Pi_{m}}{d L}=\left(w_{m}-v\right) \int_{0}^{R / L} y g(y) d y+v \mu_{Y}-\delta c_{m}, \\
\frac{d^{2} \Pi_{m}}{d L^{2}}=-\left(w_{m}-v\right) \frac{R^{2}}{L^{3}} g\left(\frac{R}{L}\right)<0 .
\end{gathered}
$$

It follows from (9) that $\Pi_{m}$ is concave. Hence, setting $d \Pi_{m} / d L=0$, we can derive (7).

4.2. The Retailer's Ordering Policy. Taking into account the response from the main supplier, the retailer's expected profit, $\Pi_{r}(Q, R)$, is given by

$$
\begin{aligned}
\Pi_{r}(Q, R)= & s E \min (X, R+Q, Y \zeta R+Q)+v E(Y \zeta R+Q-X)^{+} \\
& -c_{u} E[X-R \min (1, \zeta Y)-Q]^{+} \\
& -w_{m} R E[\min (1, \zeta Y)]-w_{b} Q
\end{aligned}
$$

The first term in (10) is the expected revenue from the sales, the second term is the earnings from salvaging the unsold products, the third term is the understock cost, and the last two terms are the cost of buying products from the two suppliers.

From (10), using the same argument as Proposition 1, we can obtain that $\Pi_{r}(Q, R)$ is jointly concave in $Q$ and $R$, and 
the unique $\left(Q^{d}, R^{d}\right)$ that maximizes $\Pi_{r}(Q, R)$ can be derived as follows.

Proposition 4. (1) If $w_{m}<w_{b}$ and $F\left(R_{0}\right) \bar{G}(1 / \zeta)+$ $\int_{0}^{1 / \zeta} F\left(y \zeta R_{0}\right) g(y) d y<\left(s-w_{b}+c_{u}\right) /\left(s-v+c_{u}\right)$, then $\left(Q^{d}, R^{d}\right)$ is uniquely solved by

$$
\begin{aligned}
& p F\left(Q^{d}\right)+F\left(Q^{d}+R^{d}\right) \bar{G}\left(\frac{1}{\zeta}\right)+\int_{0}^{1 / \zeta} F\left(Q^{d}+y \zeta R\right) g(y) d y \\
& \quad=\frac{s-w_{b}+c_{u}}{s-v+c_{u}}, \\
& F\left(Q^{d}+R^{d}\right) \bar{G}\left(\frac{1}{\zeta}\right)+\int_{0}^{1 / \zeta} F\left(Q^{d}+y \zeta R\right) \zeta y g(y) d y \\
& =\frac{s-w_{m}+c_{u}}{s-v+c_{u}}\left[\bar{G}\left(\frac{1}{\zeta}\right)+\frac{\zeta\left(\delta c_{m}-v \mu_{Y}\right)}{w_{m}-v}\right],
\end{aligned}
$$

where $R_{0}$ satisfying $F\left(R_{0}\right) \bar{G}(1 / \zeta)+\int_{0}^{1 / \zeta} F\left(y \zeta R_{0}\right) \zeta y g(y) d y=$ $\left(\left(s-w_{m}+c_{u}\right) /\left(s-v+c_{u}\right)\right)\left[\bar{G}(1 / \zeta)+\left(\zeta\left(\delta c_{m}-v \mu_{Y}\right) /\left(w_{m}-v\right)\right)\right]$ and $\bar{G}(y)=\int_{y}^{1} g(y) d y$.

(2) If $w_{m}<w_{b}$ and $F\left(R_{0}\right) \bar{G}(1 / \zeta)+\int_{0}^{1 / \zeta} \bar{F}\left(y \zeta R_{0}\right) g(y) d y \geqslant$ $\left(s-w_{b}+c_{u}\right) /\left(s-v+c_{u}\right)$, then $\left(Q^{d}, R^{d}\right)=\left(0, R_{0}\right)$.

(3) If $w_{m} \geqslant w_{b}$, then $\left(Q^{d}, R^{d}\right)=\left(F^{-1}\left(\left(s-w_{b}+c_{u}\right) /(s-v+\right.\right.$ $\left.\left.\left.c_{u}\right)\right), 0\right)$.

Proof. Similar to the proof of Proposition 2.

Given the retailer's optimal order quantity $Q^{d}$ and $R^{d}$, the retailer's expected profit is

$$
\begin{aligned}
\Pi_{r}^{d}= & \left(s-v+c_{u}\right) \\
& \times\left[\pi\left(Q^{d}, \zeta R^{d}\right)-\int_{1 / \zeta}^{1} \int_{R^{d}+Q^{d}}^{y \zeta R^{d}+Q^{d}} x f(x) g(y) d x d y\right] \\
& -c_{u} \mu_{X},
\end{aligned}
$$

and the backup supplier's expected profit and the main supplier's expected profit are $\Pi_{b}^{d}=\left(w_{b}-c_{b}\right) Q^{d}$ and $\Pi_{m}^{d}=$ $\left(w_{m}-v\right) \bar{G}(1 / \zeta) R^{d}$, respectively. Let $\Pi_{d}\left(Q^{d}, R^{d}\right)$ denote the total expected profit of the decentralized supply chain, then we have the following proposition.

Proposition 5. $\Pi_{d}\left(Q^{d}, R^{d}\right)<\Pi_{c}\left(Q^{c}, L^{c}\right)$.

Proposition 5 indicates that the decentralized supply chain's expected profit will be lower than that of an integrated supply chain. This phenomenon is well known as double marginalization [23]. It also shows the importance of supply chain coordination. From the main supplier's first-order condition; if $w_{m} \rightarrow \delta c_{m} / \mu_{Y}$, we have $\zeta \rightarrow 1$ and $L^{d}(R) \rightarrow$ $R$. Furthermore, if $w_{b} \rightarrow c_{b}$, then we have $L^{d}=L^{c}$ and $Q^{d}=$ $Q^{c}$ by the retailer's first-order conditions (11). In other words, the total expected profit of the decentralized supply chain is closer to the integrated system as the two supplier's wholesale price approaches their production cost, respectively.

\section{Supply Chain Coordination}

5.1. Overproduction Risk Sharing Contract. Risk sharing is one of the most common method of achieving supply chain coordination. This method aligns the objectives of the supply chain members and coordinates their activities to optimize system performance. The OPRS contract ensures the main supplier's risk of producing too many units (compared to the quantity ordered) being shared by the retailer [40]. Under the OPRS contract, the retailer commits to pay for all units produced by the main supplier. But he only pays the wholesale price $w_{m}$ per unit for the order quantity $R$, and quantities that exceed this amount are compensated at a discount price $w_{d}$ per unit. In order to guarantee that the main supplier is willing to sell the surplus products to the retailer and prevent the main supplier from producing an unlimited amount, we assume that $v<w_{d}<\delta c_{m} / \mu_{Y}$.

Under the OPRS contract, the main supplier's expected profit is

$$
\Pi_{m}(L)=w_{m} E \min (Y L, R)+w_{d} E(Y L-R)^{+}-\delta c_{m} L .
$$

Proposition 6. For given $R$, the main supplier's optimal planned production quantity $L^{d}(R)=\zeta_{c} R$, where $\zeta_{c}$ is independent of $R$ and satisfies

$$
\left(w_{m}-w_{d}\right) \int_{0}^{1 / \zeta_{c}} y g(y) d y=\delta c_{m}-w_{d} \mu_{Y} .
$$

Proof. Similar to the proof of Proposition 3.

Given the main supplier's best response function $L^{d}(R)=$ $\zeta_{c} R$, the retailer's expected profit can be written as follows:

$$
\begin{aligned}
\Pi_{r}(Q, R)= & s E \min (X, Y L+Q)+v E(Y L+Q-X)^{+} \\
& -c_{u} E[X-Y L-Q]^{+} \\
& -\left[w_{m} E \min \left(\zeta_{c} Y, 1\right)+w_{d} E\left(\zeta_{c} Y-1\right)^{+}\right] R \\
& -w_{b} Q .
\end{aligned}
$$

Proposition 7. The OPRS contract cannot coordinate the supply chain.

Although the OPRS contract can reduce the main supplier's overproduction risk, it increases the retailer's overstock risk. Hence, the retailer will not choose the order quantity that is the same as the integrated supply chain. But if the suppliers are willing to pay the retailer back for unsold products, then the supply chain coordination may be achieved. In the next subsection, we will construct a combined contract with a side payment to coordinate the supply chain.

5.2. Overproduction Risk Sharing with Buy-Back and a Payment from/to the Backup Supplier. This contract is a mixture 
of overproduction risk sharing and buy-back contracts. For simplification, it is assumed that the main supplier deliver all of his products at the whole price $w_{m}$ (i.e., $\mathrm{w}_{m}=w_{d}$ ) whether his actual output of the product is more than the retailer's order quantity or not, and he will buy all of the retailer's unsold products back with a return price $w_{r}$ per unit at the end of the selling season; for example, the main supplier can disassemble the unsold products and remanufacture at a lower production cost. We assume that $w_{r}-v>w_{m}-$ $\delta c_{m} / \mu_{Y}$ to avoid the triviality of the main supplier producing an infinite amount (this inequality implies that the main supplier's compensation for a unsold product is more than the profit that he earns for the sale of it). Note that the main supplier may return the unsold quantities that exceed his output, for example, the unsold products will be $Y L+Q-X>$ $Y L$ if $X<Q$ (in this case, the main supplier also returns some of the backup supplier's products). Hence, in order to compensate for the main supplier's product recycling risk, the backup supplier pays a side payment $T(>0)$ to him. If $T<0$, it can be interpreted that the main supplier gives some reimbursement to the backup supplier for coordination, since he produce more products and earns more profit when the supply chain is coordinated. Hence the parameter $T$ is adopted to split the expected profit of the coordinated system between two suppliers, and the parameter $T$ can be interpreted as that the two suppliers share their expected profits.

Under the above combined contract, the expected profit for the retailer, the main supplier and the backup supplier are given by

$$
\begin{gathered}
\Pi_{r}=s E[\min (X, Y L+Q)]+w_{r} E(Y L+Q-X)^{+} \\
-w_{m} E(Y L)-w_{b} Q \\
\Pi_{m}=w_{m} E(Y L)-\left(w_{r}-v\right) E(Y L+Q-X)^{+}-\delta c_{m} L+T \\
\Pi_{b}=\left(w_{b}-c_{b}\right) Q-T
\end{gathered}
$$

respectively.

Proposition 8. For given $Q$, if $Q<F^{-1}\left(\left(w_{m}-\delta c_{m} / \mu_{Y}\right) /\left(w_{r}-\right.\right.$ $v)$ ), then the main supplier's optimal planned production quantity $L^{d}(Q)$ is uniquely solved from

$$
\left(w_{r}-v\right) \int_{0}^{1} F\left(y L^{d}(Q)+Q\right) y g(y) d y=w_{m} \mu_{Y}-\delta c_{m}
$$

otherwise if $Q \geqslant F^{-1}\left(\left(w_{m}-\delta c_{m} / \mu_{Y}\right) /\left(w_{r}-v\right)\right)$, then $L^{d}(Q)=0$.

Proof. Taking the first and second derivatives of (15) with respect to $L$, we have

$$
\begin{aligned}
& \frac{d \Pi_{m}}{d L}=w_{m} \mu_{Y}-\delta c_{m}-\left(w_{r}-v\right) \int_{0}^{1} F(y L+Q) y g(y) d y \\
& \frac{d^{2} \Pi_{m}}{d L^{2}}=-\left(w_{r}-v\right) \int_{0}^{1} f(y L+Q) y^{2} g(y) d y<0 .
\end{aligned}
$$

It follows from (20) that $\Pi_{m}$ is concave on $L$ for given $Q$. If $Q<$ $F^{-1}\left(\left(w_{m}-\delta c_{m} / \mu_{Y}\right) /\left(w_{r}-v\right)\right)$, then $\lim _{L \rightarrow 0}\left(d \Pi_{m} / d L\right)=\left[w_{m}-\right.$ $\left.\left(w_{r}-v\right) F(Q)\right] \mu_{Y}-\delta c_{m}>0$ and $\lim _{L \rightarrow \infty}\left(d \Pi_{m} / d L\right)=\left(w_{m}-\right.$ $\left.w_{r}+v\right) \mu_{Y}-\delta c_{m}<0$, and hence there exists a unique $L^{d}(R)$ that satisfies the first-order condition in (18). Otherwise if $Q \geqslant$ $F^{-1}\left(\left(w_{m}-\delta c_{m} / \mu_{Y}\right) /\left(w_{r}-v\right)\right)$, then $d \Pi_{m} / d L \leqslant 0$ for $L>0$ and hence $L^{d}(Q)=0$.

Set

$$
\begin{aligned}
& w_{0}=s+ c_{u}-\left(s-v+c_{u}\right) \\
& \times {\left[\frac{\pi\left(Q^{d}, \zeta R^{d}\right)}{\pi\left(Q^{c}, L^{c}\right)}\right.} \\
&\left.-\frac{1}{\pi\left(Q^{c}, L^{c}\right)} \int_{1 / \zeta}^{1} \int_{R^{d}+Q^{d}}^{y \zeta R^{d}+Q^{d}} x f(x) g(y) d x d y\right] \\
& T_{\min }=\left(w_{r}-v\right)\left[\pi\left(Q^{c}, L^{c}\right)-\frac{\left(s-c_{b}+c_{u}\right) Q^{c}}{s-v+c_{u}}\right] \\
&-\left(w_{m}-v\right) \bar{G}\left(\frac{1}{\zeta}\right) R^{d}, \\
& T_{\max }=\left(w_{b}-c_{b}\right)\left(Q^{c}-Q^{d}\right)
\end{aligned}
$$

then we have the following proposition.

Proposition 9. Under the combined contracts, if

$$
\begin{gathered}
w_{m}=\frac{\delta c_{m}}{\mu_{Y}}+\frac{\left[\left(s+c_{u}\right) \mu_{Y}-\delta c_{m}\right]\left(w_{r}-v\right)}{\left(s-v+c_{u}\right) \mu_{Y}}, \\
w_{b}=c_{b}+\frac{\left(s-c_{b}+c_{u}\right)\left(w_{r}-v\right)}{s-v+c_{u}},
\end{gathered}
$$

$w_{r} \in\left[v, w_{0}\right]$ and $T \in\left[T_{\min }, T_{\max }\right]$, then the supply chain can be coordinated.

Proposition 10. Under the combined contract and contract parameters in (25), an arbitrary allocation of the optimal supply chain profit among the three members can be achieved by varying $w_{r}$ and $T$.

Proposition 9 shows that the expected profit of the integrated supply chain can be shared with any specified ratios among three members. A simply effective but not exclusive way to set the profit allocated ratios is to let them equal to the profit ratios between the corresponding members before introducing the contracts, which can certainly ensure that each entity earns more as the contracts increase the total profit of the channel.

\section{Numerical Examples}

In this section, we provide some numerical examples to gain further insights. We assume that the retailer's demand follows 


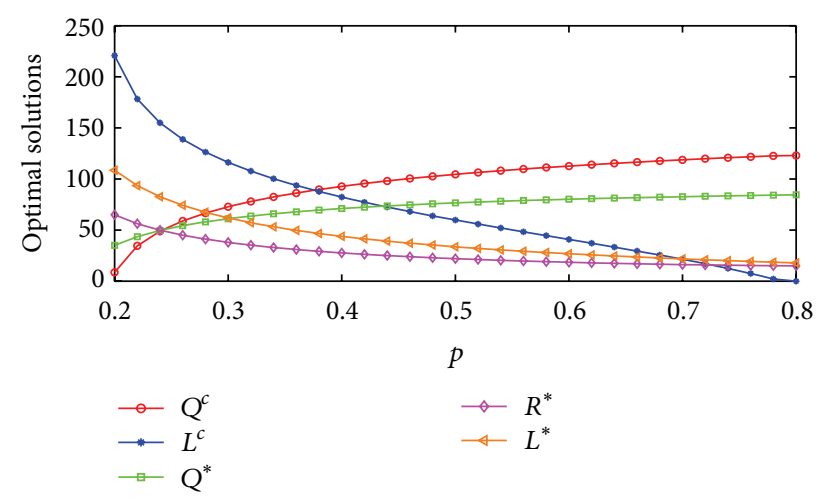

FIGURE 1: Effect of disruption probability on optimal solutions.

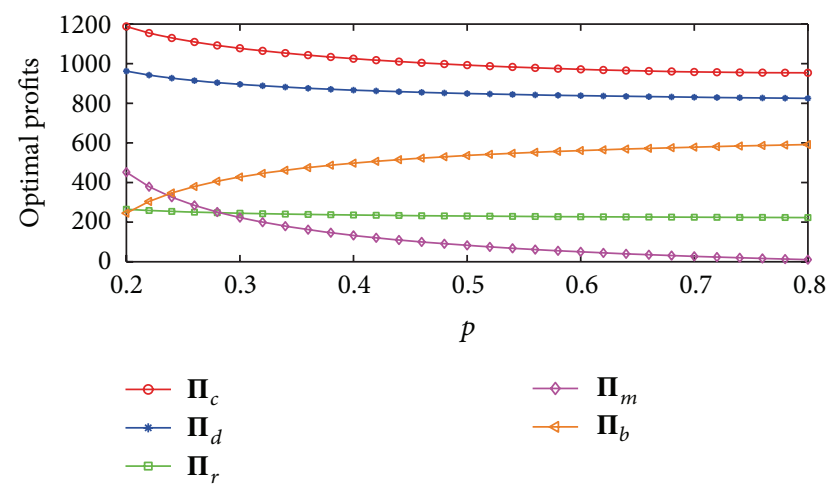

FIGURE 2: Effect of disruption probability on optimal profits.

a normal distribution with mean $\mu_{X}=1000$ and standard deviation $\sigma_{X}=200$. We also specify that $g(y)=q /(b-a)$, where $0 \leqslant a<b \leqslant 1$. Hence, the main supplier's yield has a mean of $\mu_{Y}=(a+b) q / 2$ and a standard deviation of $\sigma_{Y}=\sqrt{\left[(4-3 q)(a+b)^{2}-4 a b\right] q /(2 \sqrt{3})}$. The base values of the parameters are set as follows: $p=0.25 ; c_{m}=4, c_{b}=11$, $c_{u}=2, v=3, s=25, w_{m}=16, w_{b}=18, \alpha=0.25, a=0.4$, $b=1, \mu_{X}=100, \sigma_{X}=50$.

6.1. Effect of the Disruption Probability. Under different values of $p$, we plot the optimal solutions in Figure 1 and plot the corresponding optimal profits in Figure 2, for the centralized and decentralized systems, respectively.

Figure 1 shows that the order quantity from the backup supplier increases and the planned production quantity of the main supplier decreases as $p$ increases. Since larger disruption probability results in greater supply risk of the main supplier, the retailer will order more products from the backup supplier who has no production risk for avoiding risk increases, and the main supplier will decrease his production in order to reduce the production risk.

Figure 2 shows that an increase in the disruption probability $p$ decreases the profits of both the retailer and the main supplier. But this is not the case for the backup supplier. Since the retailer's order quantity from the backup supplier increases with the disruption probability. For all values of $p$, the integrated supply chain's profit is significantly lager than the total expected profit of the three members in the decentralized supply chain.

6.2. Effect of the Random Uncertainty and Demand Uncertainty. Tables 1 and 2 present the profits of the supply chain with and without coordination under different yield and different demand, respectively, where $\left(Q^{*}, L^{*}, \zeta^{*}\right)=$ $\left(Q^{d}, L^{d}, L^{d} / R^{d}\right)$ in the decentralized model and $\left(Q^{*}, L^{*}, \zeta^{*}\right)=$ $\left(Q^{c}, L^{c}, 1\right)$ in the centralized model. Table 1 shows that the profits of three members decrease as the yield uncertainty increases, which gives the main supplier an incentive to decrease the planned production quantity for reducing yield uncertainty. Since the retailer also greatly benefits from the decrease in the yield uncertainty, he has an incentive to help the supplier to reduce the uncertainty through increasing the return price, and to place a larger order from the backup supplier for transferring the main supplier's supply risk. Table 2 indicates that lower demand uncertainty benefits the retailer and the backup supplier, but this is not the case for the main suppliers. Since the retailer will order smaller quantities as the demand variability decreases, it will directly reduce the main supplier's profit. We can also from Table 2 find that $\zeta^{*}$ is invariant. This is true for the reason that $\zeta^{*}$ is independent of the demand.

From Tables 1 and 2, we find that the retailer's expected profit significantly decreases and as the suppliers' whole price increase without coordination. Supply chain coordination greatly benefits the retailer and the whole supply chain, and this becomes more obvious when the demand uncertainty is more severe. We also see that the coordinated supply chain can achieve Pareto improvement by choosing the appropriate contract parameters $w_{r}$ and $T$.

\section{Conclusion}

In this paper, we consider a supply chain including one retailer and two suppliers under random demand and random yield, where the yield is subject to disruption with a determinate probability. Both the centralized scenario and decentralized scenario are studied, and the retailer's optimal ordering policy and the main supplier's optimal planned production quantity are provided. In the decentralized setting, we propose a combined contract that is a combination of OPRS and buy-back contracts with an additional side payment to component regarding the worse performing supplier. With the combined contract, the appropriate whole price and return price can coordinate the supply and allocate the integrate supply chain's profit with any specified ratios between the retailer and the two suppliers, and the side payment can further split 
TABLE 1: Impact of different yield variabilities on the supply chain.

\begin{tabular}{|c|c|c|c|c|c|c|c|c|c|}
\hline Models & Contract parameters & $(a, b)$ & $Q^{*}$ & $L^{d}$ & $\zeta^{*}$ & $\Pi_{r}$ & $\Pi_{m}$ & $\Pi_{b}$ & Total \\
\hline \multirow{9}{*}{$\begin{array}{l}\text { Decentralized model under traditional } \\
\text { arrangement }\left(w_{m}, w_{b}\right)\end{array}$} & \multirow{3}{*}{$(17.96,20.18)$} & $(0.50,0.90)$ & 17.59 & 114.78 & 1.61 & 92.11 & 556.49 & 161.48 & 810.08 \\
\hline & & $(0.45,0.95)$ & 19.62 & 114.46 & 1.63 & 91.13 & 531.74 & 180.11 & 802.98 \\
\hline & & $(0.40,1.00)$ & 22.33 & 112.25 & 1.65 & 89.71 & 501.86 & 205.02 & 796.59 \\
\hline & \multirow{3}{*}{$(18.40,20.52)$} & $(0.50,0.90)$ & 16.49 & 112.83 & 1.61 & 63.84 & 563.02 & 156.96 & 783.82 \\
\hline & & $(0.45,0.95)$ & 18.51 & 112.46 & 1.63 & 62.90 & 537.68 & 176.29 & 776.87 \\
\hline & & $(0.40,1.00)$ & 21.22 & 110.21 & 1.65 & 61.56 & 507.10 & 202.06 & 770.71 \\
\hline & \multirow{3}{*}{$(18.84,20.86)$} & $(0.50,0.90)$ & 15.34 & 110.91 & 1.61 & 36.33 & 569.10 & 151.27 & 756.70 \\
\hline & & $(0.45,0.95)$ & 17.36 & 110.49 & 1.63 & 35.45 & 543.19 & 171.26 & 749.89 \\
\hline & & $(0.40,1.00)$ & 20.07 & 108.20 & 1.65 & 34.17 & 511.90 & 197.91 & 743.99 \\
\hline \multirow{9}{*}{$\begin{array}{l}\text { Coordination under the combined } \\
\text { contract }\left(w_{m}, w_{b}, w_{r}, T\right)\end{array}$} & \multirow{3}{*}{$(17.9,20.18,16.5,240)$} & $(0.50,0.90)$ & 45.64 & 158.91 & 1.00 & 359.20 & 596.39 & 178.95 & 1134.54 \\
\hline & & $(0.45,0.95)$ & 49.85 & 152.91 & 1.00 & 355.88 & 553.78 & 217.65 & 1127.32 \\
\hline & & $(0.40,1.00)$ & 54.29 & 146.27 & 1.00 & 352.12 & 508.64 & 258.39 & 1119.15 \\
\hline & \multirow{3}{*}{$(18.40,20.52,17.0,250)$} & $(0.50,0.90)$ & 45.64 & 158.91 & 1.00 & 330.48 & 619.59 & 184.46 & 1134.54 \\
\hline & & $(0.45,0.95)$ & 49.85 & 152.91 & 1.00 & 327.31 & 575.41 & 224.60 & 1127.32 \\
\hline & & $(0.40,1.00)$ & 54.29 & 146.27 & 1.00 & 323.71 & 528.59 & 266.85 & 1119.15 \\
\hline & \multirow{3}{*}{$(18.84,20.86,17.5,260)$} & $(0.50,0.90)$ & 45.64 & 158.91 & 1.00 & 301.77 & 642.79 & 189.98 & 1134.54 \\
\hline & & $(0.45,0.95)$ & 49.85 & 152.91 & 1.00 & 298.73 & 597.03 & 231.55 & 1127.32 \\
\hline & & $(0.40,1.00)$ & 54.29 & 146.27 & 1.00 & 295.31 & 548.54 & 275.31 & 1119.15 \\
\hline
\end{tabular}

TABLE 2: Impact of different demand variabilities on the supply chain.

\begin{tabular}{|c|c|c|c|c|c|c|c|c|c|}
\hline Models & Contract parameters & $\left(\mu_{X}, \sigma_{X}\right)$ & $Q^{*}$ & $L^{d}$ & $\zeta^{*}$ & $\Pi_{r}$ & $\Pi_{m}$ & $\Pi_{b}$ & Total \\
\hline \multirow{9}{*}{$\begin{array}{l}\text { Decentralized model under traditional } \\
\text { arrangement }\left(w_{m}, w_{b}\right)\end{array}$} & \multirow{3}{*}{$(18.40,20.52)$} & $(100,40)$ & 37.63 & 87.41 & 1.65 & 135.49 & 402.17 & 358.24 & 895.90 \\
\hline & & $(100,45)$ & 29.52 & 98.70 & 1.65 & 97.72 & 454.14 & 281.05 & 832.91 \\
\hline & & $(100,50)$ & 21.22 & 110.21 & 1.65 & 61.56 & 507.10 & 202.06 & 770.71 \\
\hline & \multirow{3}{*}{$(18.84,20.86)$} & $(100,40)$ & 36.73 & 85.76 & 1.65 & 106.70 & 405.76 & 362.17 & 874.62 \\
\hline & & $(100,45)$ & 28.50 & 96.86 & 1.65 & 69.62 & 458.29 & 281.03 & 808.94 \\
\hline & & $(100,50)$ & 20.07 & 108.20 & 1.65 & 34.17 & 511.90 & 197.91 & 743.99 \\
\hline & \multirow{3}{*}{$(19.28,21.20)$} & $(100,40)$ & 35.79 & 84.13 & 1.65 & 78.53 & 408.99 & 365.10 & 852.61 \\
\hline & & $(100,45)$ & 27.43 & 95.04 & 1.65 & 42.22 & 462.05 & 279.84 & 784.10 \\
\hline & & $(100,50)$ & 18.87 & 106.20 & 1.65 & 7.56 & 516.30 & 192.46 & 716.32 \\
\hline \multirow{9}{*}{$\begin{array}{l}\text { Coordination under the combined } \\
\text { contract }\left(w_{m}, w_{b}, w_{r}, T\right)\end{array}$} & \multirow{3}{*}{$(18.40,20.52,17.0,240)$} & $(100,40)$ & 63.64 & 117.35 & 1.00 & 348.63 & 459.98 & 365.85 & 1174.45 \\
\hline & & $(100,45)$ & 58.99 & 131.86 & 1.00 & 336.06 & 488.69 & 321.63 & 1146.38 \\
\hline & & $(100,50)$ & 54.29 & 146.27 & 1.00 & 323.71 & 518.59 & 276.85 & 1119.15 \\
\hline & \multirow{3}{*}{$(18.84,20.86,17.5,250)$} & $(100,40)$ & 63.64 & 117.35 & 1.00 & 319.13 & 477.84 & 377.48 & 1174.45 \\
\hline & & $(100,45)$ & 58.99 & 131.86 & 1.00 & 307.12 & 507.57 & 331.69 & 1146.38 \\
\hline & & $(100,50)$ & 54.29 & 146.27 & 1.00 & 295.31 & 538.54 & 285.31 & 1119.15 \\
\hline & \multirow{3}{*}{$(19.28,21.20,18,260)$} & $(100,40)$ & 63.64 & 117.35 & 1.00 & 289.64 & 495.69 & 389.12 & 1174.45 \\
\hline & & $(100,45)$ & 58.99 & 131.86 & 1.00 & 278.18 & 526.45 & 341.75 & 1146.38 \\
\hline & & $(100,50)$ & 54.29 & 146.27 & 1.00 & 266.90 & 558.48 & 293.77 & 1119.15 \\
\hline
\end{tabular}


the profit between the main supplier and the backup supplier. Numerical examples show that coordination can greatly benefit the retailer and the whole supply chain, and that the coordinated supply chain can achieve Pareto improvement by choosing the appropriate contract parameters.

One direct extension of this work is to study the proposed model under risk measures such as expected utility objective, mean-variance criterion, and conditional value-at-risk. Another extension is to consider our problems with asymmetric information on various factors such as the random yield and the random demand. We leave these problems for further research.

\section{Appendix}

Proof of Proposition 1. From (1), the first-order and secondorder partial derivatives with respect to $L$ and $Q$, respectively, are given by

$$
\begin{aligned}
\frac{\partial \Pi_{c}}{\partial Q}= & -\left(s-v+c_{u}\right)\left[p F(Q)+\int_{0}^{1} F(y L+Q) g(y) d y\right] \\
& +s-c_{b}+c_{u},
\end{aligned}
$$

$$
\begin{aligned}
\frac{\partial \Pi_{c}}{\partial L}= & -\left(s-v+c_{u}\right) \int_{0}^{1} y F(y L+Q) g(y) d y \\
& +\left(s+c_{u}\right) \mu_{Y}-\delta c_{m},
\end{aligned}
$$

$$
\begin{aligned}
& \frac{\partial^{2} \Pi_{c}}{\partial Q^{2}} \\
& \quad=-\left(s-v+c_{u}\right)\left[p f(Q)+\int_{0}^{1} f(y L+Q) g(y) d y\right]<0,
\end{aligned}
$$

$$
\begin{aligned}
& \frac{\partial^{2} \Pi_{c}}{\partial L^{2}}=-\left(s-v+c_{u}\right) \int_{0}^{1} y^{2} f(y L+Q) g(y) d y<0, \text { (A.4) } \\
& \frac{\partial^{2} \Pi_{c}}{\partial Q \partial L}=\frac{\partial^{2} \Pi_{c}}{\partial L \partial Q}=-\left(s-v+c_{u}\right) \int_{0}^{1} y f(y L+Q) g(y) d y .
\end{aligned}
$$

Furthermore, it is easy to verify that

$$
\begin{aligned}
& {\left[\begin{array}{ll}
\frac{\partial^{2} \Pi_{c}}{\partial Q^{2}} & \frac{\partial^{2} \Pi_{c}}{\partial Q \partial L} \\
\frac{\partial^{2} \Pi_{c}}{\partial L \partial Q} & \frac{\partial^{2} \Pi_{c}}{\partial L^{2}}
\end{array}\right]} \\
& =\frac{\partial^{2} \Pi_{c}}{\partial Q^{2}} \frac{\partial^{2} \Pi_{c}}{\partial L^{2}}-\left(\frac{\partial^{2} \Pi_{c}}{\partial Q \partial L}\right)^{2}
\end{aligned}
$$

$$
\begin{aligned}
&=p\left(s-v+c_{u}\right)^{2} f(Q) \int_{0}^{1} f(y L+Q) g(y) d y \\
&-\left(s-v+c_{u}\right)^{2}\left\{\int_{0}^{1} y^{2} f(y L+Q) g(y) d y\right. \\
& \times \int_{0}^{1} f(y L+Q) g(y) d y \\
&\left.-\left(\int_{0}^{1} y f(y L+Q) g(y) d y\right)^{2}\right\} \\
& \geqslant p\left(s-v+c_{u}\right)^{2} f(Q) \int_{0}^{1} f(y L+Q) g(y) d y>0,
\end{aligned}
$$

where the the first inequality follows from the CauchySchwarz inequality. Therefore, the Hessian matrix of $\Pi(Q, L)$ is a negative definite matrix, which implies that $\Pi_{c}(Q, L)$ is jointly concave in $(Q, L)$.

Proof of Proposition 2. (i) From (A.4), it is obvious that $\partial \Pi_{c} / \partial L$ is a decreasing function of $L$ for given $Q$. Let $Q_{0}=$ $F^{-1}\left(\left(\left(s+c_{u}\right) \mu_{Y}-\delta c_{m}\right) /\left(s-v+c_{u}\right) \mu_{Y}\right)$, then for given $Q \in\left[0, Q_{0}\right]$, since $\left.\left(\partial \Pi_{c} / \partial L\right)\right|_{L=0}>0$ and $\left.\left(\partial \Pi_{c} / \partial L\right)\right|_{L \rightarrow \infty}=v \mu_{Y}-\delta c_{m}<0$, there exists a unique optimal $L^{c}(Q)$ that satisfies the firstorder condition in (4). Substituting $L=L^{c}(Q)$ into (2), we have

$$
\begin{aligned}
& \frac{\partial \Pi_{c}\left(Q, L^{c}(Q)\right)}{\partial Q} \\
& =-\left(s-v+c_{u}\right) \\
& \quad \times\left[p F(Q)+\int_{0}^{1} F\left(y L_{1}^{c}(Q)+Q\right) g(y) d y\right] \\
& \quad+s-c_{b}+c_{u} .
\end{aligned}
$$

Taking the first-order derivative with respect to $Q$ in (A.1), we get

$$
\int_{0}^{1} y\left(y \frac{d L^{c}(Q)}{d Q}+1\right) f\left(y L^{c}(Q)+Q\right) g(y) d y=0 .
$$

From (A.8), we have

$$
\frac{d L^{c}(Q)}{d Q}=-\frac{\int_{0}^{1} y f\left(y L^{c}(Q)+Q\right) g(y) d y}{\int_{0}^{1} y^{2} f\left(y L^{c}(Q)+Q\right) g(y) d y}<-1
$$

for all $Q \in\left[0, Q_{0}\right]$. By (A.8)-(A.9), we can conclude that there exists a unique constant $\lambda \in(0,1)$ such that

$$
\lambda \frac{d L^{c}(Q)}{d Q}= \begin{cases}\leqslant-1, & y \leqslant \lambda, \\ >-1, & y>\lambda .\end{cases}
$$


Since

$$
\begin{aligned}
0= & \int_{0}^{\lambda} y\left(y \frac{d L^{c}(Q)}{d Q}+1\right) f\left(y L^{c}(Q)+Q\right) g(y) d y \\
& +\int_{\lambda}^{1} y\left(y \frac{d L^{c}(Q)}{d Q}+1\right) f\left(y L^{c}(Q)+Q\right) g(y) d y \\
\leqslant & \lambda\left[\int_{0}^{\lambda}\left(y \frac{d L^{c}(Q)}{d Q}+1\right) f\left(y L^{c}(Q)+Q\right) g(y) d y\right. \\
& \left.+\int_{\lambda}^{1}\left(y \frac{d L^{c}(Q)}{d Q}+1\right) f\left(y L^{c}(Q)+Q\right) g(y) d y\right] \\
\leqslant & \int_{0}^{1}\left(y \frac{d L^{c}(Q)}{d Q}+1\right) f\left(y L^{c}(Q)+Q\right) g(y) d y,
\end{aligned}
$$

hence, we have

$$
\begin{aligned}
& \frac{d^{2} \Pi_{c}\left(Q, L^{c}(Q)\right)}{d Q^{2}} \\
& \quad=-p f(Q)-\int_{0}^{1}\left(y \frac{d L^{c}(Q)}{d Q}+1\right) f\left(y L^{c}(Q)+Q\right) g(y) d y \\
& \quad<0
\end{aligned}
$$

which implies that $\Pi_{c}\left(Q, L^{c}(Q)\right)$ is concave in $Q$.

As a result, if $\delta c_{m}<c_{b} \mu_{Y}$ and $\int_{0}^{1} F\left(y L_{0}\right) g(y) d y<(s-$ $\left.c_{b}+c_{u}\right) /\left(s-v+c_{u}\right)$, then $Q_{0}>F^{-1}\left(\left(s-c_{b}+c_{u}\right) /\left(s-v+c_{u}\right)\right)$, and we have $\left.\left(d \Pi_{c}\left(Q, L^{c}(Q)\right) / d Q\right)\right|_{Q=Q_{0}}=\delta c_{m} / \mu_{Y}-c_{b}<0$ and $\left.\left(d \Pi_{c}\left(Q, L^{c}(Q)\right) / d Q\right)\right|_{Q=0}=-\left(s-v+c_{u}\right) \int_{0}^{1} F\left(y L_{0}\right) g(y) d y+$ $s-c_{b}+c_{u}>0$. Hence there exists a unique $Q^{c} \in\left(0, Q_{0}\right)$ such that $d \Pi_{c}\left(Q, L^{c}(Q)\right) / d Q=0$, and the optimal $L^{c}(Q)$ is solved from $\int_{0}^{1} y F\left(y L^{c}\left(Q^{c}\right)+Q^{c}\right) g(y) d y=\left(\left(s+c_{u}\right) \mu_{Y}-\delta c_{m}\right) /(s-v+$ $\left.c_{u}\right)$. That is, $\left(Q^{c}, L^{c}\right)$ can be uniquely solved by the first-order conditions in (3)-(4).

(ii) If $\delta c_{m}<c_{b} \mu_{Y}$ and $\int_{0}^{1} F\left(y L_{0}\right) g(y) d y \geqslant\left(s-c_{b}+c_{u}\right) /$ $\left(s-v+c_{u}\right)$, then $Q_{0}>F^{-1}\left(\left(s-c_{b}+c_{u}\right) /(s-v+\right.$ $\left.\left.c_{u}\right)\right),\left.\left(d \Pi_{c}\left(Q, L^{c}(Q)\right) / d Q\right)\right|_{Q=Q_{0}}<0$ and $\left(d \Pi_{c}\left(Q, L^{c}(Q)\right) /\right.$ $d Q)\left.\right|_{Q=0}<0$. Hence $\Pi_{c}\left(Q, L^{c}(Q)\right)$ is decreasing on $Q \in$ $\left[0, Q_{0}\right]$. Furthermore, it follows from (A.2) that $L^{c}(Q)=0$ for all $Q>Q_{0}$. When $L^{c}(Q)=0$, we can obtain that $\Pi_{c}(Q, 0)$ is decreasing on $Q \in\left(Q_{0}, \infty\right)$ since $d \Pi_{c}(Q, 0) / d Q<0$ for all $Q>Q_{0}$. Hence, we have $Q^{c}=0$ and $L^{c}=L_{0}$.

(iii) If $\delta c_{m} \geqslant c_{b} \mu_{Y}$, then $Q_{0} \leqslant F^{-1}\left(\left(s-c_{b}+c_{u}\right) /(s-v+\right.$ $\left.\left.c_{u}\right)\right)$ and $\left.\left(d \Pi_{c}\left(Q, L^{c}(Q)\right) / d Q\right)\right|_{Q=Q_{0}} \geqslant 0$. Hence $\Pi_{c}\left(Q, L^{c}(Q)\right)$ is increasing on $Q \in\left[0, Q_{0}\right]$. When $Q>Q_{0}$, it is easy to verify that $\Pi_{c}\left(Q, L^{c}(Q)\right)=\Pi_{c}(Q, 0)$ has the maximum value at the point $Q=F^{-1}\left(\left(s-c_{b}+c_{u}\right) /\left(s-v+c_{u}\right)\right)\left(>Q_{0}\right)$. Hence, we obtain that $\Pi_{c}\left(Q, L^{c}(Q)\right)$ has the maximum value at $Q=F^{-1}((s-$ $\left.\left.c_{b}+c_{u}\right) /\left(s-v+c_{u}\right)\right)$ for all $Q \geqslant 0$, and we have $\left(Q^{c}, L^{c}\right)=$ $\left(F^{-1}\left(\left(s-c_{b}+c_{u}\right) /\left(s-v+c_{u}\right)\right), 0\right)$.
Proof of Proposition 5. From Proposition 3, the total expected profit of the decentralized supply chain can be expressed as follows:

$$
\begin{aligned}
& \Pi_{d}\left(Q^{d}, R^{d}\right) \\
& =p\left\{\int_{0}^{Q^{d}}\left[(s-v) x+v Q^{d}\right] f(x) d x\right. \\
& \left.+\int_{Q^{d}}^{\infty}\left[\left(s+c_{u}\right) Q^{d}-c_{u} x\right] f(x) d x\right\} \\
& +\int_{0}^{1 / \zeta}\left\{\int_{0}^{y \zeta R^{d}+Q^{d}}\left[(s-v) x+v\left(y \zeta R^{d}+Q^{d}\right)\right] f(x) d x\right. \\
& +c_{b} Q^{d}-\delta c_{m} \zeta R^{d} . \\
& +\int_{y \zeta R^{d}+Q^{d}}^{\infty}\left\{\int_{0}^{R^{d}+Q^{d}}\left[(s-v) x+v c^{d}\right] f(x) d x\right. \\
& \left.+\int_{R^{d}+Q^{d}}^{\infty}\left[\left(s-v+c_{u}\right)\left(Q^{d}+R^{d}\right)+v Q^{d}+Q^{d}\right)-c_{u} x\right] \\
& \times f(x) d x\} g(y) d y \\
& \left.\left.+c_{u} x\right] f(x) d x+v y \zeta R^{d}\right\} g(y) d y
\end{aligned}
$$

For given $Q \geqslant 0$, let

$$
\begin{aligned}
& K(R \mid Q) \\
& =\int_{0}^{R+Q}[(s-v) x+v Q] f(x) d x \\
& \quad+\int_{R+Q}^{\infty}\left[\left(s-v+c_{u}\right)(Q+R)+v Q-c_{u} x\right] f(x) d x,
\end{aligned}
$$

then

$$
\frac{d K(R \mid Q)}{d R}=\left(s-v+c_{u}\right)[1-F(Q+R)]>0,
$$


which implies that $K(R \mid Q)$ is an increasing function of $R$. Hence, we get

$$
\begin{aligned}
& \int_{1 / \zeta}^{1}\left[K\left(R^{d} \mid Q^{d}\right)+v y \zeta R^{d}\right] g(y) d y \\
& <\int_{1 / \zeta}^{1}\left[K\left(y \zeta R^{d} \mid Q^{d}\right)+v y \zeta R^{d}\right] g(y) d y \\
& =\int_{1 / \zeta}^{1}\left\{\int_{0}^{Q^{d}+y \zeta R}\left[(s-v) x+v\left(y \zeta R^{d}+Q^{d}\right)\right] f(x) d x\right. \\
& \left.\quad+\int_{Q^{d}+y \zeta R^{d}}^{\infty}\left[\left(s+c_{u}\right)\left(Q^{d}+y \zeta R^{d}\right)-c_{u} x\right] f(x) d x\right\} \\
& \quad \times g(y) d y .
\end{aligned}
$$

As a result, we have $\Pi_{d}\left(Q^{d}, R^{d}\right)<\Pi_{c}\left(Q^{d}, \zeta R^{d}\right) \leqslant \Pi_{c}\left(Q^{c}, L^{c}\right)$.

Proof of Proposition 7. Take the first derivatives with $Q$ and $R$ in (15), we have

$$
\begin{aligned}
\frac{\partial \Pi_{r}}{\partial Q}= & \left(s-w_{b}+c_{u}\right)-\left(s-v+c_{u}\right) \\
& \times\left[p F(Q)+\int_{0}^{1} F(y \eta R+Q) g(y) d y\right], \\
\frac{\partial \Pi_{r}}{\partial R}= & {\left[\left(s+c_{u}\right) \mu_{Y}-\delta c_{m}\right.} \\
& \left.-\left(s-v+c_{u}\right) \int_{0}^{1} F(y \eta R+Q) y g(y) d y\right] \eta \\
& -\left(w_{m}-w_{d}\right) \bar{G}\left(\frac{1}{\eta}\right) .
\end{aligned}
$$

By comparing (A.17) with (A.1)-(A.2), we find that $Q^{d}=Q^{c}$ and $R^{d}=L^{c} / \eta$ if and only if $w_{b}=c_{b}$ and $w_{m}=w_{d}$. However, if $w_{b}=c_{b}$, then the backup supplier's expected profit is equal to zero, and $w_{m}=w_{d}$ will result in the main supplier producing an infinite amount. Hence, the OPRS contract cannot coordinate the supply chain.

Proof of Proposition 9. From (15), we get

$$
\begin{aligned}
\frac{d \Pi_{r}}{d Q}= & \left(s+c_{u}-w_{r}\right)\left[p F(Q)+\int_{0}^{1} F(y L+Q) g(y) d y\right] \\
& +s-w_{b}+c_{u}, \\
\frac{d \Pi_{m}}{d L}= & w_{m} \mu_{Y}-\delta c_{m}-\left(w_{r}-v\right) \int_{0}^{1} F(y L+Q) y g(y) d y .
\end{aligned}
$$

If conditions in (21)-(22) are fulfilled, then by comparing (A.18) with (A.1)-(A.2), we obtain $d \Pi_{r} / d Q=\partial \Pi_{c} / \partial L$ and $d \Pi_{m} / d L=\partial \Pi_{c} / \partial L$. Hence, we have $Q^{d}=Q^{c}$ and $L^{d}\left(Q^{d}\right)=$ $L^{c}$.

If the supply chain coordination is achieved, then the expected profits for the retailer, the main supplier, and the backup supplier are $\Pi_{m}^{c}=\left(s-w_{r}+c_{u}\right) \pi\left(Q^{c}, L^{c}\right)-c_{u} \mu_{X} \Pi_{m}^{c}=$ $\left(w_{r}-v\right)\left[\pi\left(Q^{c}, L^{c}\right)-\left(s-c_{b}+c_{u}\right) Q^{c} /\left(s-v+c_{u}\right)\right]+T$ and $\Pi_{b}^{c}=\left(w_{b}-c_{b}\right) Q^{c}-T$, respectively. The contract $\left(w_{r}, T\right)$ will not be accepted unless the three member's expected profit is better than the reservation expected profit. Hence, by solving $\Pi_{i}^{c} \geqslant \Pi_{i}^{d}$, for $i=r, m, b$, we get $w_{r} \leqslant w_{0}$ and the feasible range of $T$, which is $\left[T_{\min }, T_{\max }\right]$.

Proof of Proposition 10. For any given nonnegative numbers $\phi_{r}, \phi_{m}$, and $\phi_{b}$ that satisfy $\phi_{r}+\phi_{m}+\phi_{b}=1$, if $w_{r}=\phi_{r} v+$ $\left(\phi_{m}+\phi_{b}\right)\left(s+c_{u}-c_{u} \mu_{X} / \pi\left(Q^{c}, L^{c}\right)\right)$ and $T=\left(w_{r}-v\right)[(s-$ $\left.\left.c_{b}+c_{u}\right) Q^{c} /\left(s-v+c_{u}\right)-\phi_{b} \pi\left(Q^{c}, L^{c}\right) /\left(\phi_{m}+\phi_{b}\right)\right]$, then we have $\Pi_{r}^{c}: \Pi_{m}^{c}: \Pi_{b}^{c}=\phi_{r}: \phi_{m}: \phi_{b}$.

\section{Acknowledgments}

The authors would like to thank the editor and the anonymous referees for their helpful comments on earlier versions of this paper. This research was supported in part by the National Natural Science Foundation of China (no. 71002106) and the Independent Innovation Fund of Tianjin University (no. 2012XZ091).

\section{References}

[1] C. Yano and H. Lee, "Lot sizing with random yields: a review," Operations Research, vol. 43, no. 2, pp. 311-334, 1995.

[2] H. Gurnani, R. Akella, and J. Lehoczky, "Optimal order policies in assembly systems with random demand and random supplier delivery," IIE Transactions, vol. 28, no. 11, pp. 865-878, 1996.

[3] K. Moinzadeh and H. L. Lee, "Approximate order quantities and reorder points for inventory systems where orders arrive in two shipments," Operations Research, vol. 37, no. 2, pp. 277-287, 1989.

[4] Y. Gerchak and A. Grosfeld-Nir, "Multiple lot-sizing, and value of probabilistic information, in production to order of an uncertain size," International Journal of Production Economics, vol. 56-57, pp. 191-197, 1998.

[5] D. Granot and S. Yin, "On sequential commitment in the price-dependent news vendor model," European Journal of Operational Research, vol. 177, no. 2, pp. 939-968, 2007.

[6] S. K. Mukhopadhyay and H. Ma, "Joint procurement and production decisions in remanufacturing under quality and demand uncertainty," International Journal of Production Economics, vol. 120, no. 1, pp. 5-17, 2009.

[7] C. X. Wang, "Random yield and uncertain demand in decentralised supply chains under the traditional and vmi arrangements," International Journal of Production Research, vol. 47, no. 7, pp. 1955-1968, 2009.

[8] Y. J. He and J. Zhang, "Random yield supply chain with a yield dependent secondary market," European Journal of Operational Research, vol. 206, no. 1, pp. 221-230, 2010.

[9] Y. He and X. Zhao, "Coordination in multi-echelon supply chain under supply and demand uncertainty," International Journal of Production Economics, vol. 139, no. 1, pp. 106-115, 2012. 
[10] H. Gurnani, R. Akella, and J. Lehoczky, "Supply management in assembly systems with random yield and random demand," IIE Transactions, vol. 32, no. 8, pp. 701-714, 2000.

[11] M. G. Güler and T. Bilgiç, "On coordinating an assembly system under random yield and random demand," European Journal of Operational Research, vol. 196, no. 1, pp. 342-350, 2009.

[12] B. Keren, "The single-period inventory problem: extension to random yield from the perspective of the supply chain," Omega, vol. 37, no. 4, pp. 801-810, 2009.

[13] X. Li, Y. Li, and X. Cai, "A note on the random yield from the perspective of the supply chain," Omega, vol. 40, no. 5, pp. 601610, 2012.

[14] K. B. Hendricks and V. R. Singhal, "The effect of supply chain glitches on shareholder wealth," Journal of Operation, Management, vol. 21, no. 5, pp. 501-523, 2003.

[15] S. Pochard, Managing risks of supply-chain disruptions: dual sourcing as a real option [M.S. thesis], Technology and Policy, The Massachusetts Institute of Technology, 2003.

[16] A. Oke and M. Gopalakrishnan, "Managing disruptions in supply chains: a case study of a retail supply chain," International Journal of Production Economics, vol. 118, no. 1, pp. 168-174, 2009.

[17] H. Yu, A. Z. Zeng, and L. Zhao, "Single or dual sourcing: decision-making in the presence of supply chain disruption risks," Omega, vol. 37, no. 4, pp. 288-300, 2009.

[18] A. Sarkar and P. K. J. Mohapatra, "Determining the optimal size of supply base with the consideration of risks of supply disruptions," International Journal of Production Economics, vol. 119, no. 1, pp. 122-135, 2009.

[19] B. Tomlin, "On the value of mitigation and contingency strategies for managing supply-chain disruption risks," Science, vol. 52, no. 5, pp. 639-657, 2006.

[20] P. L. Meena, S. P. Sarmah, and A. Sarkar, "Sourcing decisions under risks of catastrophic event disruptions," Transportation Research E, vol. 47, no. 6, pp. 1058-1074, 2011.

[21] J. Li, S. Wang, and T. Cheng, "Competition and cooperation in a single-retailer two-supplier supply chain with supply disruption," International Journal of Production Economics, vol. 124, no. 1, pp. 137-150, 2010.

[22] L. V. Snyder and Z. J. M. Shen, "Supply and demand uncertainty in multi-echelon supply chains," in Working Paper, P.C. Rossin College of Engineering and Applied Sciences, Lehigh University, Bethlehem, Pa , USA, 2006.

[23] J. Spengler, "Vertical integration and antitrust policy," Journal of Political Economy, vol. 58, no. 4, pp. 347-352, 1950.

[24] B. Pasternack, "Optimal pricing and returns policies for perishable commodities," Marketing Science, vol. 4, no. 2, pp. 166-176, 1985.

[25] H. Emmons and S. N. Gilbert, "The role of returns policies in pricing and inventory decisions for catalogue goods," Science, vol. 44, no. 2, pp. 276-283, 1998.

[26] S. Webster and S. K. Weng, "A risk-free perishable item returns policy," Manufacturing \& Service Operations Management, vol. 2, no. 1, pp. 100-106, 2000.

[27] Y. Gerchak and Y. Wang, "Revenue-sharing vs. wholesaleprice contracts in assembly systems with random demand," Production and Operations Management, vol. 13, no. 1, pp. 23-33, 2004.

[28] G. P. Cachon and M. A. Lariviere, "Supply chain coordination with revenue-sharing contracts: strength and limitation," Management Science, vol. 51, no. 1, pp. 30-44, 2005.
[29] M. A. Lariviere and E. L. Porteus, "Selling to the newsvendor: an analysis of price-only contracts," Manufacture \& Service Operations Management, vol. 3, no. 4, pp. 293-305, 2001.

[30] C. L. Li and P. Kouvelis, "Flexible and risk-sharing supply contracts under price uncertainty," Management Science, vol. 45, no. 10, pp. 1378-1398, 1999.

[31] C. Corbett and X. Groote, "A supplier's optimal quantity discount policy under asymmetric information," Manage-Ment Science, vol. 46, no. 3, pp. 444-450, 2000.

[32] A. A. Tsay, "The quantity flexibility contract and suppliercustomer incentives," Management Science, vol. 45, no. 10, pp. 1339-1358, 1999.

[33] T. A. Taylor, "Coordination under channel rebates with sales effort effect," Management Science, vol. 48, no. 8, pp. 992-1007, 2002.

[34] D. Ding and J. Chen, "Coordinating a three level supply chain with flexible return policies," Omega, vol. 36, no. 5, pp. 865-876, 2008.

[35] Y. He, X. Zhao, L. Zhao, and J. He, "Coordinating a supply chain with effort and price dependent stochastic demand," Applied Mathematical Modelling, vol. 33, no. 6, pp. 2777-2790, 2009.

[36] T. Xiao, K. Shi, and D. Yang, "Coordination of a supply chain with consumer return under demand uncertainty," International Journal of Production Economics, vol. 124, no. 1, pp. 171180, 2010.

[37] B. van der Rhee, J. A. A. van der Veen, V. Venugopal, and V. R. Nalla, "A new revenue sharing mechanism for coordinating multi-echelon supply chains," Operations Research Letters, vol. 38, no. 4, pp. 296-301, 2010.

[38] Z. Lin, C. Cai, and B. Xu, "Supply chain coordination with insurance contract," European Journal of Operational Research, vol. 205, no. 2, pp. 339-345, 2010.

[39] X. Li, Y. Li, and X. Cai, "Double marginalization and coordination in the supply chain with uncertain supply," European Journal of Operational Research, vol. 226, no. 2, pp. 228-236, 2013.

[40] Y. He and J. Zhang, "Random yield risk sharing in atwo-level supply chain," International Journal of Production Economics, vol. 112, no. 2, pp. 769-781, 2008.

[41] J. Hou, A. Z. Zeng, and L. Zhao, "Coordination with a backup supplier through buy-back contract under supply disruption under supply disruption," Transportation Research E, vol. 46, no. 6, pp. 881-895, 2010.

[42] R. D. H. Warburton and R. Stratton, "The optimal quantity of quick response manufacturing for an onshore and offshore sourcing model," International Journal of Logistics: Research and Applications, vol. 8, no. 2, pp. 125-141, 2005. 


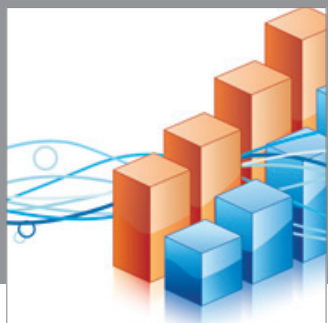

Advances in

Operations Research

mansans

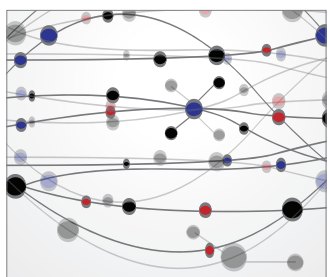

The Scientific World Journal
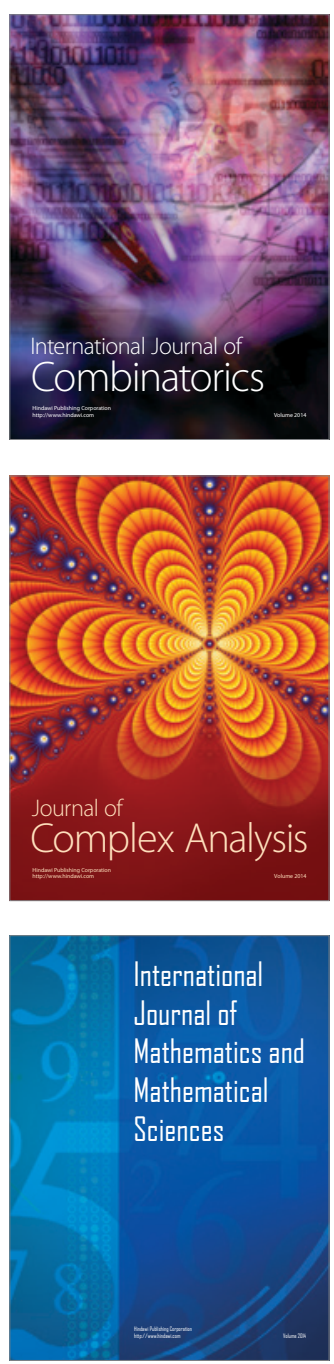
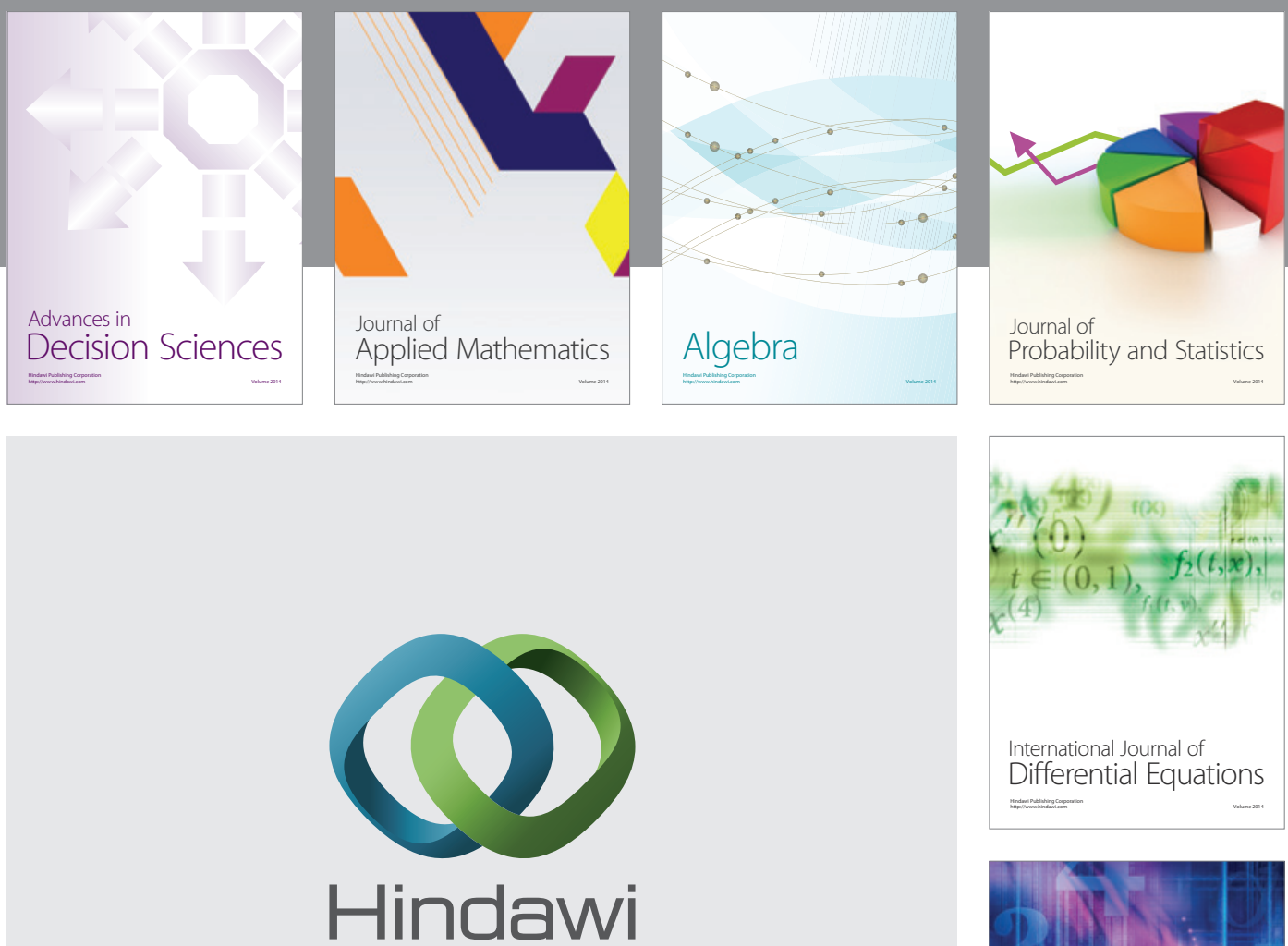

Submit your manuscripts at http://www.hindawi.com
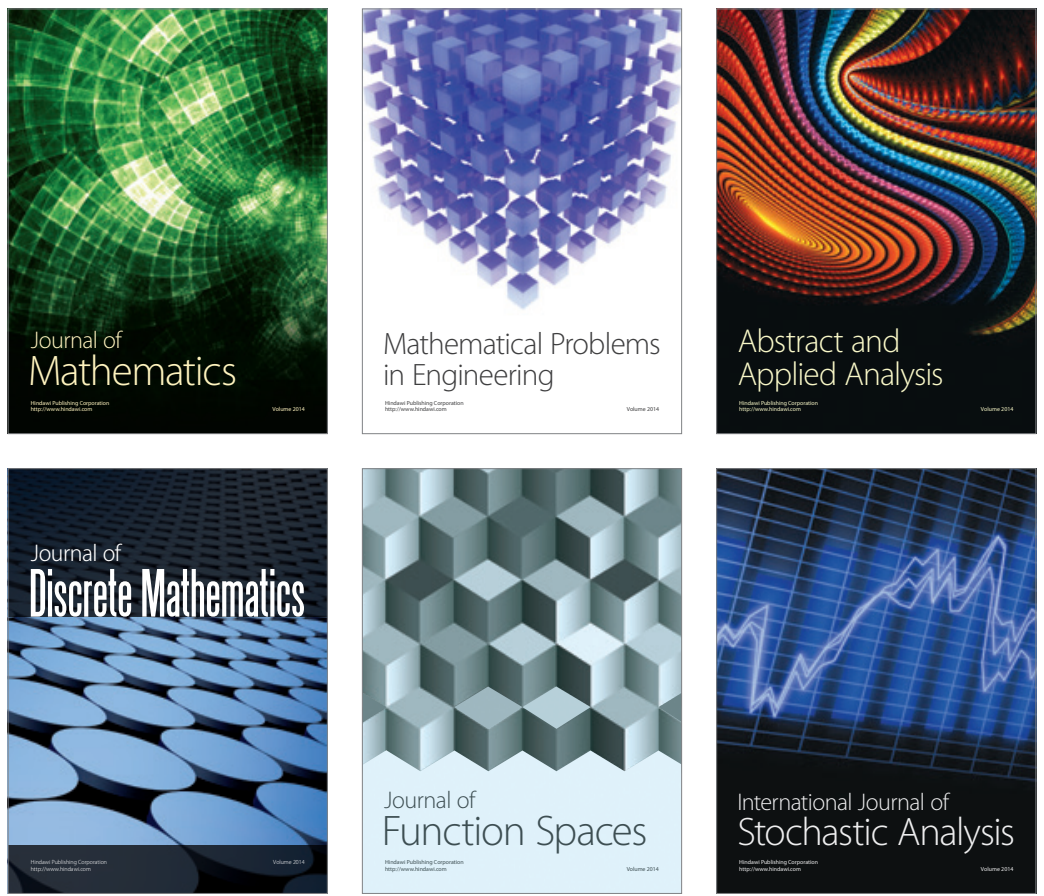

Journal of

Function Spaces

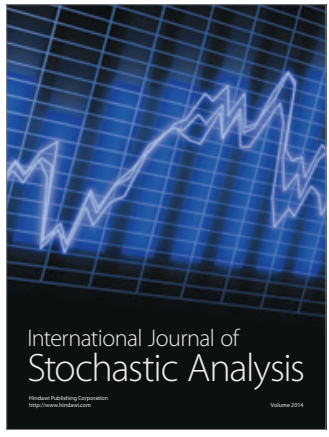

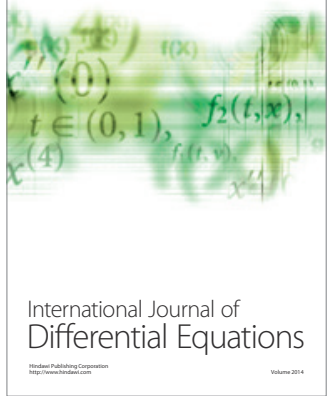
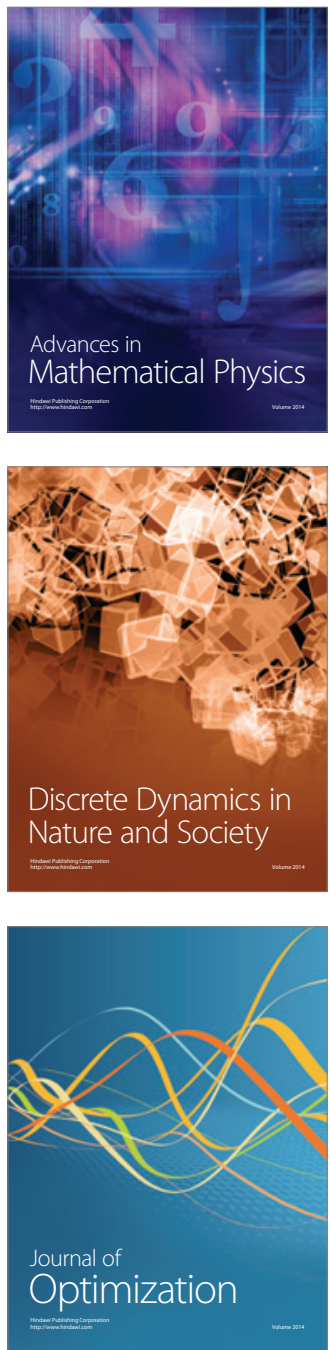